Texas Southern University

Digital Scholarship @ Texas Southern University

Faculty Publications

8-1-2021

\title{
Age-and Region-Dependent Disposition of Raloxifene in Rats
}

\author{
Ting Du \\ Texas Southern University \\ Rongjin Sun \\ University of Houston \\ Imoh Etim \\ Texas Southern University \\ Zicong Zheng \\ University of Houston \\ Dong Liang \\ Texas Southern University
}

See next page for additional authors

Follow this and additional works at: https://digitalscholarship.tsu.edu/facpubs

\section{Recommended Citation}

Du, Ting; Sun, Rongjin; Etim, Imoh; Zheng, Zicong; Liang, Dong; Hu, Ming; and Gao, Song, "Age-and RegionDependent Disposition of Raloxifene in Rats" (2021). Faculty Publications. 10.

https://digitalscholarship.tsu.edu/facpubs/10

This Article is brought to you for free and open access by Digital Scholarship @ Texas Southern University. It has been accepted for inclusion in Faculty Publications by an authorized administrator of Digital Scholarship @ Texas Southern University. For more information, please contact haiying.li@tsu.edu. 


\section{Authors}

Ting Du, Rongjin Sun, Imoh Etim, Zicong Zheng, Dong Liang, Ming Hu, and Song Gao 


\title{
Age-and Region-Dependent Disposition of Raloxifene in Rats
}

\author{
Ting Du' • Rongjin Sun ${ }^{2} \cdot$ Imoh Etim ' • Zicong Zheng ${ }^{2}$ • Dong Liang ' • Ming Hu² • Song Gao ' (D)
}

Received: 27 April 2021 / Accepted: 15 July 2021 / Published online: 28 July 2021

(C) The Author(s), under exclusive licence to Springer Science+Business Media, LLC, part of Springer Nature 2021

\begin{abstract}
Purpose Raloxifene undergoes extensive glucuronidation in the gastrointestinal (GI) tract and the liver. However, the impact of age on raloxifene disposition has never been studied. The purpose of this paper is to determine glucuronidation and Pharmacokinetics (PK) profiles of raloxifene in rats at different ages.

Methods Raloxifene glucuronidation was characterized using S9 fractions prepared from different intestinal segments and the liver of F344 rats at 4-, 11-, and 28-week. PK studies were conducted to determine raloxifene oral bioavailability at different ages. Raloxifene and its glucuronides were quantified using LC-MS/MS.

Results Raloxifene-6-glucuronide and raloxifene-4'-glucuronide were detected as the major metabolites and the ratio of these two glucuronides were different ranging from 2.1 to 4.9 folds in the ileum, jejunum, liver, and duodenum, and from 14.5 to 50 folds in the colon. The clearances in the duodenum at 4-week for both two glucuronides were significantly lower than those at the other two ages. PK studies showed that the oral bioavailability of raloxifene is age dependent. The absolute oral bioavailability of raloxifene was 3.5-folds higher at 4week compared to that at 11-weeks. When raloxifene was
\end{abstract}

Ting Du and Rongjin Sun contributed equally to this work.

Ming Hu

mhu@uh.edu

Song Gao

song.gao@tsu.edu

Department of Pharmaceutical Science, College of Pharmacy and Health Sciences, Texas Southern University, 3100 Cleburne St, Houston, Texas 77004, USA

2 Department of Pharmacological and Pharmaceutical Sciences, College of Pharmacy, The University of Houston, 490 I Calhoun Street,

Houston, Texas 77204, USA administered through IV bolus, its half-life was $5.9 \pm 1.16 \mathrm{~h}$ and $3.7 \pm 0.68 \mathrm{~h}$ at 11 -and 4 -week, respectively.

Conclusion These findings suggested that raloxifene metabolism in the duodenum was significantly slower at young age in rats, which increased the oral bioavailability of raloxifene. At 11-week, enterohepatic recycling efficiency was higher than that of 4-week. Raloxifene's dose at different ages should be carefully considered.

KEYWORDS Raloxifene · age · glucuronidation · PK

\section{INTRODUCTION}

Raloxifene (Fig. 1), a selective estrogen-receptor modulator, is a mixed agonist and antagonist of estrogen receptor in different tissues (1). Several large and long-term clinical trials showed that raloxifene increased bone mineral density and reduced the risk of fracture in postmenopausal women (2-4). Raloxifene was approved for the treatment and prevention of osteoporosis in postmenopausal women using Evista as the brand name. Other than the approved indication, raloxifene was also found to be associated with reduced breast cancer in postmenopausal women (5). In addition, raloxifene has been continuously tested at different ages for the treatment of different types of diseases, such as middle-aged (18-50 years) patients with schizophrenia (6), middle to old-age (4070 years) patients with refractory schizophrenia (7), and middle to old-age (55-86 years) patients with Castration-Resistant Prostate Cancer (8). Raloxifene was also tested in pediatric patients for the management of persistent pubertal gynecomastia (mean age 14.6 years) (9).

Raloxifene disposition has been well studied in adults or using adult animals. After being taken orally, approximately $60 \%$ of raloxifene is rapidly absorbed in the gastrointestinal tract. However, the absolute oral bioavailability of raloxifene in human is only $2 \%(10)$ due to rapid metabolism in the 
Fig. I The structure of raloxifene and its glucuronide metabolites (raloxifene-6-glucuronide, raloxifene-4'-glucuronide).

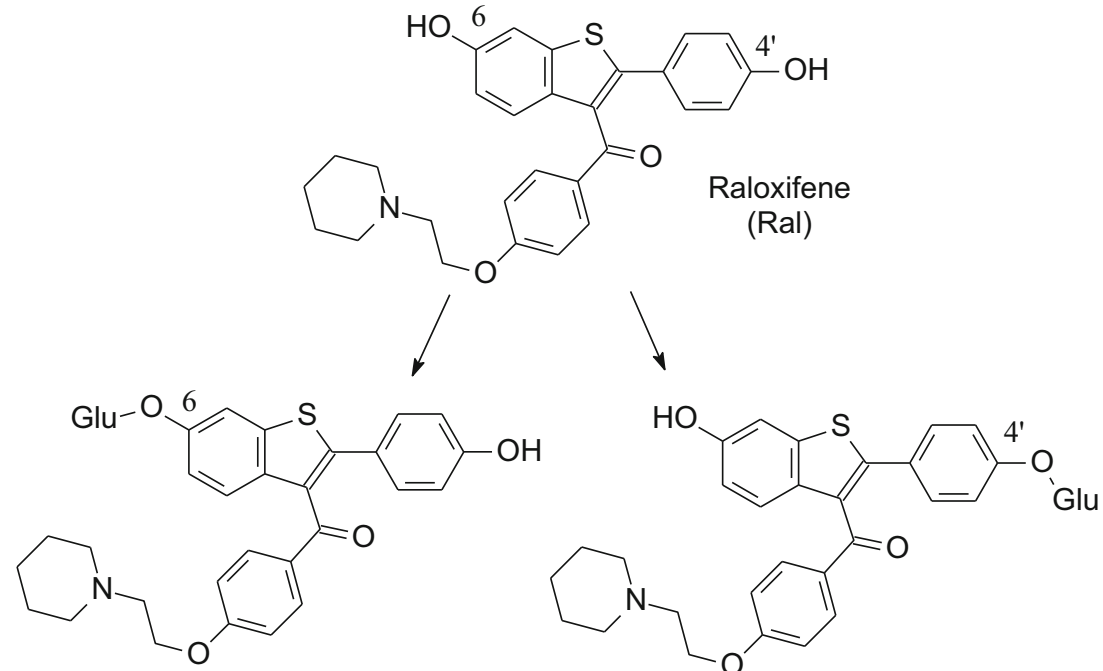

Raloxifene-6-glucuronide

(Ral-6-G)
Raloxifene-4'-glucuronide

(Ral-4'-G) gastrointestinal (GI) tract and the liver. The major metabolites of raloxifene are raloxifene-6-glucuronide (Ral-6-G) and raloxifene-4'-glucuronide (Ral-4'-G) (Fig. 1) mediated by different isoforms of glucuronosyltransferase (UGT/Ugt) including UGT1A1, 1A6, 1A8 and 1A10. Due to expression variations of these UGT isoforms, the production of these two major metabolites in the GI tract and the liver could be different. For example, we found previously that Ral-4'-G is the major metabolite in the intestine while both metabolites are produced in the liver when incubated with human tissue microsomes (11). In addition, raloxifene may undergo enterohepatic recycling through glucuronidation and de-glucuronidation, which enhances the impact of glucuronidation in the GI tract and the liver on systemic exposure of raloxifene.

Currently, the doses used in most of the clinical trials regardless the age were $60 \mathrm{mg} /$ day, which was suggested to be used in postmenopausal women. However, raloxifene disposition could be age-dependent because expression of the involved metabolic enzymes (i.e., UGTs) is age-dependent. Disposition variation could cause different drug exposure in the plasma at different ages. The aim of the present study was to determine the impact of age on raloxifene glucuronidation and in vivo exposure using F344 rats.

\section{MATERIALS AND METHODS}

\section{Chemicals and Reagents}

Raloxifene hydrochloride ( $\mathrm{Ral}$ ), raloxifene-6-O-glucuronide (Ral-6-G), and raloxifene-4'-O-glucuronide (Ral-4'-G) were purchased from Toronto Research Chemicals (Toronto, Canada, all compounds purity $\geq 99 \%$ ). $\mathrm{MgCl}_{2}$, saccharolactone, alamethicin, formononetin, and UDPGA were purchased from Sigma-Aldrich (St. Louis, MO), water, methanol, and acetonitrile are LC-MS grade and purchased from EMD (Gibbstown, NJ, USA). The primary polyclonal antibodies against Ugtla and $\beta$-actin was purchased from (Cell Signaling Technology, Inc., MA). The polyvinylidene fluoride membranes were obtained from Millipore Corporation (MA, USA).

\section{Animals}

Female F344 rats were obtained from Harlan Laboratory (Indianapolis, IN), and housed in the animal facility at the University of Houston within an environmentally controlled room (temperature, $23-27^{\circ} \mathrm{C}$, humidity, 45-55\%, and $12 \mathrm{~h}$ dark-light cycle) with free access of water and a standard diet. The animal study was approved by the IACUC at the University of Houston.

\section{Tissue Enzyme S9 Preparation}

The liver and intestine S9 fractions were prepared from F344 rats aged 4, 11, and 28 weeks according to the protocol published by us previously $(12,13)$. Briefly, rats $(n=6)$ at $4(80 \pm$ $10 \mathrm{~g}), 11(150 \pm 10 \mathrm{~g})$, or $28(250 \pm 10 \mathrm{~g})$ weeks were fasted overnight and sacrificed to collect the liver and intestine tissues. The fresh tissues were flushed with cold buffer to remove the blood and luminal content, and then humorized followed by centrifugation at $9000 \times \mathrm{g}$ for $15 \mathrm{mins}$ at $4^{\circ} \mathrm{C}$ to afford $\mathrm{S} 9$ fractions. The protein concentrations were measured using the Pierce ${ }^{\text {TM }}$ BCA Protein Assay Kit (Thermos Scientific, USA). 


\section{Glucuronidation Reaction}

The glucuronidation reaction was carried out using a standard protocol described in our previous publication (14). Briefly, tissue $\mathrm{S} 9$ fractions, $\mathrm{MgCl}_{2}(5 \mathrm{mM})$, saccharolactone $(4.4 \mathrm{mM})$, alamethicin $(0.022 \mathrm{mg} / \mathrm{ml})$, and UDPGA (3.5 $\mathrm{mM}$ ) were mixed in a $50 \mathrm{mM}$ potassium phosphate buffer (pH 79.4, total volume $170 \mu \mathrm{L}$ ). Then raloxifene (Final concentration $0.125,0.25,0.5,1,2.5,5,10,12.5,25 \mu \mathrm{M})$ was incubated in the above mixture for $60 \mathrm{~min}$ at $37^{\circ} \mathrm{C}$. The reaction was then terminated by adding $100 \mu \mathrm{L}$ acetonitrile solution containing $0.6 \%$ formic acid and $100 \mathrm{nM}$ formononetin as the internal standard (I.S.). Samples were then vortexed and centrifuged at 15,000 rpm for $15 \mathrm{~min}$ at $4^{\circ} \mathrm{C}$ for injection. A raloxifene control in phosphate buffer incubated with a boiled S9 fraction was used as the negative control.

\section{Western Blotting}

To investigate the age-related difference in glucuronidation activity, Ugt content in duodenum and liver S9 fractions samples from 4-, 11-, and 28-week rats were measured using Western blot. Aliquots of S9 fraction samples were separated on a 10\% SDS-PAGE gel using electrophoresis in a running buffer. Then, the gels were transferred to a polyvinylidene fluoride membranes and the membrane was blocked in 5\% FBS in Tris-buffered saline Tween 20 overnight, followed by incubation with Ugtla primary antibody at $4^{\circ} \mathrm{C}$ overnight in a Tris-buffered saline Tween 20 buffer at 1:1000 dilution (Cell Signaling Technology, Inc., MA). After incubation with primary antibodies, the membrane was allowed to return to room temperature, rinsed with Tris-buffered saline Tween 20 3 times, and the band visualization was achieved by incubating with appropriate horseradish peroxidase-conjugated secondary antibody and chemiluminescence agents. Densitometry analysis was conducted using a ChemiDoc MP Imaging System from Bio-Rad laboratories.

\section{Pharmacokinetic Study}

For oral administration, raloxifene $(4 \mathrm{mg} / \mathrm{ml})$ was dissolved in ethanol:PEG400:0.1\% cellulose $(1: 2: 7)$ and administered $(10 \mathrm{mg} / \mathrm{kg})$ to rats at 4 -week and 11 -week $(n=5$ or 6$)$ through oral gavage as reported previously (15). For i.v. injection, raloxifene was administered to rats at $2 \mathrm{mg} / \mathrm{kg}$ through tail vein. Blood samples (approximately 30-50 $\mu \mathrm{l}$ ) were collected by snipping the tails at $0,0.25,0.5,1,2,4,6$, and $24 \mathrm{~h}$. Plasma was afforded after centrifugation (8000 rpm, $3 \mathrm{~min}$ ) and kept at $-80^{\circ} \mathrm{C}$ freezer until analysis. Samples were prepared using the protocol published by us previously (12). Total raloxifene, Ral-6-G, and Ral-4'-G were analyzed using the published method.

\section{Data Calculation and Statistical Analysis}

Data were presented as mean \pm standard deviation. Metabolic rates were calculated using raloxifene glucuronide concentration divided by enzyme concentration and incubation time. Michaelis-Menten, Lineweaver-Burk, and EadieHofstee plots kinetic models were selected by comparison of Akaike information criterion values, lower Akaike values indicating a better-fit model will be chosen. Kinetic parameters $\mathrm{Km}$, Vmax, and intrinsic clearance (Clearance) values were obtained via nonlinear regression analysis of the MichaelisMenten equation. Two-way ANOVA was used to test the effect of age and the intestinal segment on raloxifene glucuronidation. The raloxifene pharmacokinetic data were analyzed using WinNonlin 6.3 with the non-compartmental model. Un-paired Student's t-test (Microsoft Excel) was used to analyze the PK parameters at different ages.

\section{RESULTS}

When raloxifene was incubated with the enzymes from different regions, Ral-6-G and Ral-4'-G were detected as the metabolites (Fig. 1). These two glucuronides were then quantified using a validated LC-MS method published by us previously (12). The kinetics parameters for both Ral-6-G and Ral-4'-G were more accurately modeled by MichaelisMenten in all intestinal segments and liver S9 fractions rather than by Lineweaver-Burk and Eadie-Hofstee plots kinetics.

\section{Glucuronidation Pattern at Different Ages}

The glucuronidation pattern was evaluated by incubating raloxifene at $5 \mu \mathrm{M}$ with different intestinal segments and liver S9 fractions. The results showed that Ral-6-G is the major metabolites for all regions at all ages (Fig. 2). Additionally, significant age- and segment-related differences in Ral-6-G and Ral-4'-G metabolic rates were observed. In the colon, the differences of these two metabolites were 46.7 and 50 folds at 4 and 11 weeks, while at 28 weeks, the difference is 14.5 folds. In the duodenum, the glucuronidation pattern is similar to that in the colon. At 4- and 11- week, the metabolic rates of Ral-6-G were 4.9 folds of that Ral-4'-G, while at 28-week, the ratio of these two metabolites was decreased to 3.5-fold. In the liver, the ratio of these two metabolites were similar at all ages. The ratios of these two metabolites in the other intestinal segments were slightly different.

\section{Glucuronidation Kinetics}

The total metabolic rates were calculated using the sum concentrations of Ral-6-G and Ral-4'-G and the kinetic parameters were listed in Table I. The results showed that in the 

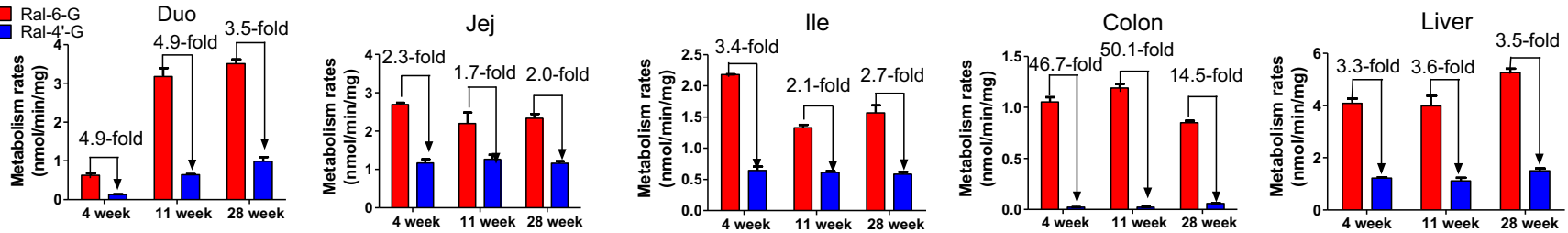

Fig. 2 Raloxifene glucuronidation pattern at different ages in different intestinal segments and liver $(n=3)$.

duodenum, the total metabolic rate increased from 4-week to 11- and 28-week (Fig. 3A; Table I). The Vmax was increased 5.9 -fold from $20.09 \pm 1.06 \mathrm{pmol} / \mathrm{mg} / \mathrm{min}$ at 4 -week to $118.50 \pm 5.34$ and $121.50 \pm 7.53 \mathrm{pmol} / \mathrm{mg} / \mathrm{min}$ at $11-$ and 28-week, respectively. Similarly, the $\mathrm{Km}$ value was also increased approximately 2-fold from 4-week to 11 - and 28week (Table I) and the Clearance was increased about 2.9 and 3.5-fold from 4-week to 11- and 28-week, respectively. When compared 28-week with 11-week, the Vmax, Km, and Clearance did not change significantly.

In the other intestinal segments, the $\mathrm{Vmax}, \mathrm{Km}$, and Clearance are various slightly (Fig. 3 B, C D, Table I) at different ages. For the liver, both $\mathrm{Vmax}$ and $\mathrm{Km}$ are similar at 4-week and 11-week but increased significantly when compared to those at 28-week. However, the liver clearance only slightly decreased from 4-week to 11- and 28-week (Table I).

To fully evaluate the glucuronidation pattern, the Vmax, $\mathrm{Km}$, and Clearance of Ral-6-G and Ral-4'-G were calculated using the data when raloxifene was incubated with S9 fractions from different regions. The results showed that both Ral6-G and Ral-4'-G metabolic rates were age-dependent in the duodenum (Figs. 4 and 5, and Table II). The Vmax and Km of these two metabolites at 4 -weeks rats were significantly lower than those at 11- and 28-weeks parameters. The Km and Vmax of the Ral-6-G was age-dependent increased from $1.224 \pm 0.330 \mu \mathrm{M}$ to $2.033 \pm 0.389$ and $1.805 \pm 0.529$, $16.71 \pm 0.97 \mathrm{pmol} / \mathrm{mg} / \mathrm{min}$ to $94.18 \pm 4.41$ and $89.96 \pm$ $6.29 \mathrm{pmol} / \mathrm{mg} / \mathrm{min}$ in duodenum, respectively. The $\mathrm{Km}$ and Vmax of the Ral-4-G were $2.1 \sim 4.9$-fold lower than $\mathrm{Km}$ and Vmax of the Ral-6-G, but they were also agedependent increased in the duodenum. Consistent with the $\mathrm{Km}$ and Vmax results, the Clearance for Ral-6-G and Ral4'-G was significantly lower at 4-week when compared to those at 11- and 28-week in the duodenum. In the jejunum and ileum regions, the Vmax and Km of Ral-6-G and Ral-4'$\mathrm{G}$ were slightly changed at different ages, but clearance in jejunum and ileum are higher at 4-week than those at 11and 28-week.

\section{Ugt I Expression in the Duodenum and the Liver}

Upon observing age-related increases in duodenum glucuronidation activity, we further examined UGT protein expression in the duodenum S9 fraction samples at different ages using Western blot. The results showed that the Ugtla expression in the duodenum at 11- and 28-
Table I Kinetic parameters of total raloxifene glucuronide (Ral-6-G + Ral-4'-G) in different regions at different ages

\begin{tabular}{|c|c|c|c|c|}
\hline \multirow[t]{2}{*}{ Kinetics parameters } & \multirow[t]{2}{*}{ Regions } & \multicolumn{3}{|l|}{ Ages(weeks) } \\
\hline & & $4 w$ & IIW & $28 w$ \\
\hline \multirow[t]{5}{*}{$\operatorname{Km}(\mu M)$} & Duodenum & $1.20 \pm 0.27$ & $2.44 \pm 0.40 *$ & $2.048 \pm 0.48^{*}$ \\
\hline & Jejunum & $1.41 \pm 0.17$ & $2.045 \pm 0.32 *$ & $2.211 \pm 0.21$ * \\
\hline & Ileum & $1.43 \pm 0.19$ & $2.153 \pm 0.30 *$ & $1.645 \pm 0.38$ \\
\hline & Colon & $1.43 \pm 0.16$ & $0.658 \pm 0.08 *$ & $0.906 \pm 0.10 *$ \\
\hline & liver & $3.18 \pm 0.19$ & $3.514 \pm 0.39$ & $7.145 \pm 0.66 * \#$ \\
\hline \multirow[t]{5}{*}{$V \max (p m o l / m g / m i n)$} & Duodenum & $20.09 \pm 1.06$ & $1 \mid 8.5 \pm 5.34 *$ & $121.50 \pm 7.53^{*}$ \\
\hline & Jejunum & $100.20 \pm 5.93$ & $89.17 \pm 5.97$ & $98.22 \pm 5.02$ \\
\hline & Ileum & $71.31 \pm 4.55$ & $57.31 \pm 4.24 *$ & $62.68 \pm 3.66^{*}$ \\
\hline & Colon & $25.95 \pm 1.44$ & $25.23 \pm 2.28$ & $19.54 \pm 0.85 * \#$ \\
\hline & liver & $178.40 \pm 3.13$ & $\mid 83.1 \pm 8.39$ & $305.5 \pm 11.25 * \#$ \\
\hline \multirow[t]{5}{*}{ Clearance } & Duodenum & $16.69 \pm 1.75$ & $48.58 \pm 4.38 *$ & $59.28 \pm 7.35^{*}$ \\
\hline & Jejunum & $71.27 \pm 4.17$ & $43.61 \pm 5.84 *$ & $44.43 \pm 4.54$ * \\
\hline & lleum & $50.04 \pm 6.38$ & $26.62 \pm 3.94 *$ & $38.11 \pm 4.45 * \#$ \\
\hline & Colon & $\mid 8.10 \pm 2.01$ & $36.78 \pm 3.74 *$ & $21.57 \pm 1.88 \#$ \\
\hline & liver & $56.13 \pm 1.98$ & $52.1 \pm 4.77$ & $42.75 \pm 3.15^{*}$ \\
\hline
\end{tabular}

*, $p<0.05$ compared with 4 weeks; \#, $p<0.05$, compared with 28 weeks (t-test) 

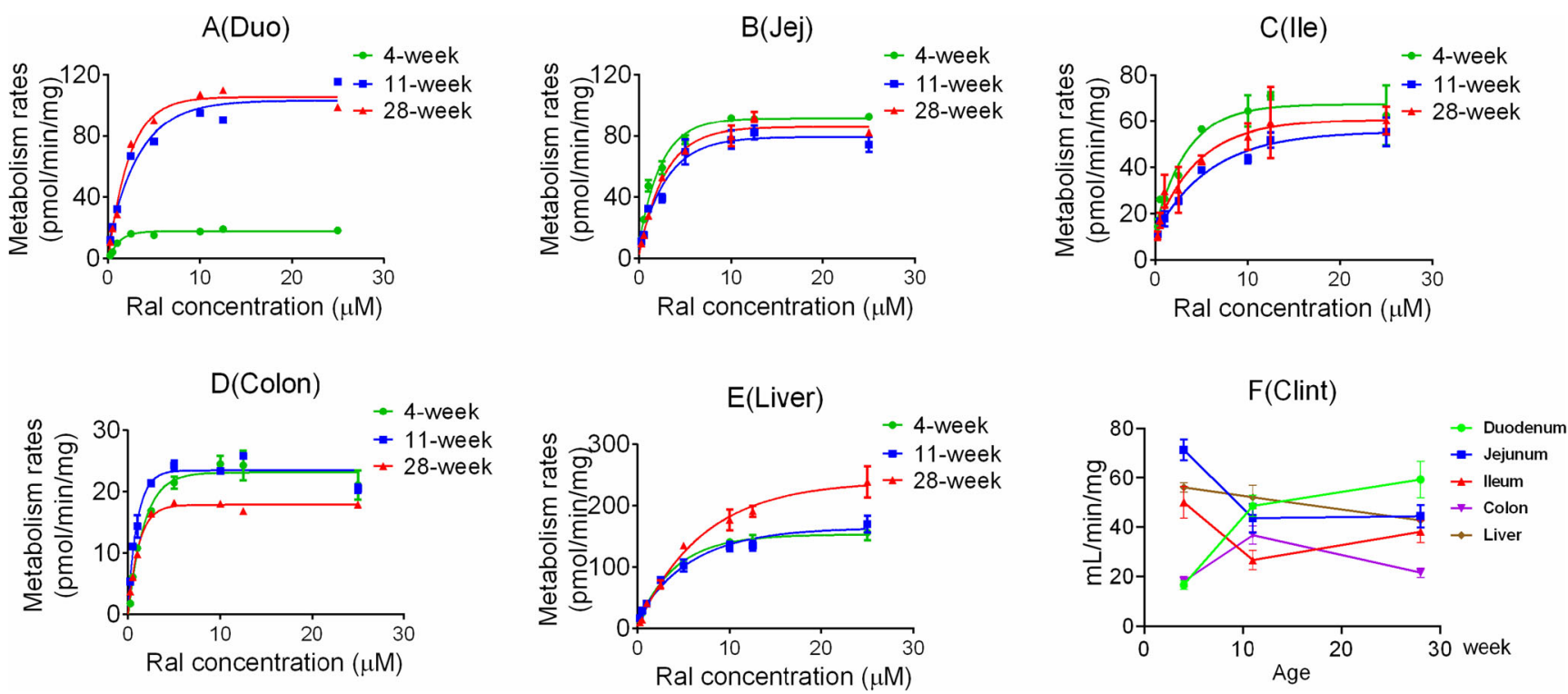

Fig. 3 Regional Glucuronidation and clearance of Raloxifene metabolism in rat S9 fraction. The glucuronidation reaction was carried out for $60 \mathrm{~min}$ at $37^{\circ} \mathrm{C}$ with $0.125,0.25,0.5,1,2.5,5,10,12.5,25 \mu \mathrm{M}$ raloxifene. The S9 fractions were made from duodenum (Duo), Jejunum (lej), ileum(lle), colon and liver used in the study, the metabolic clearance of raloxifene to metabolite by each enzyme is given as the Vmax/Km ratio. Each column represents the mean and error bars indicate the S.D $(n=3)$.

week was 3.7 and 2.8 folds higher than that of 4 -week (Fig. 7). In the liver, the expression of Ugtla was similar at all the three ages.

\section{Pharmacokinetics of Raloxifene at Different Ages in Rats}

Because the total clearance at 11 -week is similar to that at 28week, we compared the PK profile using female F344 rats at
4- and 1 1-week (Fig. 6). Total raloxifene, Ral-6-G, and Ral-4'$\mathrm{G}$ were quantified in the plasma using the robust LC-MS method published by us previously (12). The results showed when raloxifene was administered through oral route, the plasma $\mathrm{AUC}_{0-\mathrm{t}}$ of raloxifene at 4 -weeks $(4456.78 \pm$ $1328.32 \mathrm{nmol} \mathrm{h} / \mathrm{L}$ ) was about 3.6-fold higher than that at 11 -week (1254.57 $\pm 296.07 \mathrm{nmol} \mathrm{h} / \mathrm{L}$, Fig. 6A, Table IV). The absolute oral bioavailability $\left(\mathrm{F}^{\%} \%\right)$ of raloxifene was significantly higher at 4-week $(75.4 \%)$ compared to that at 11-week
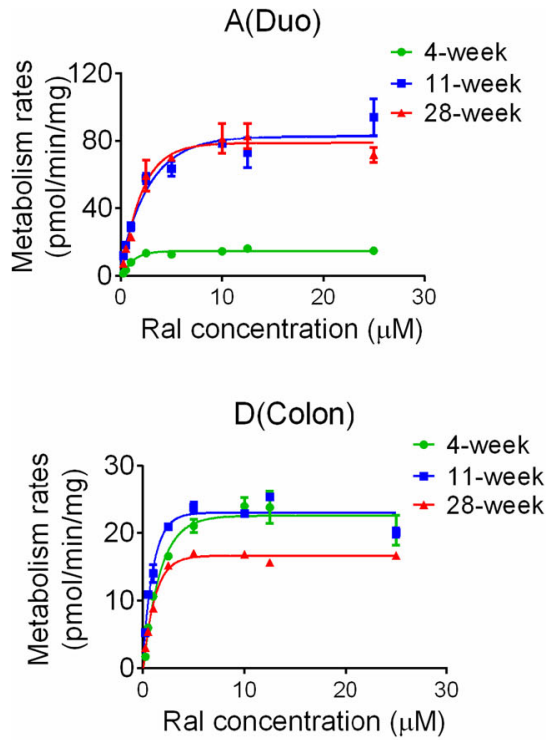
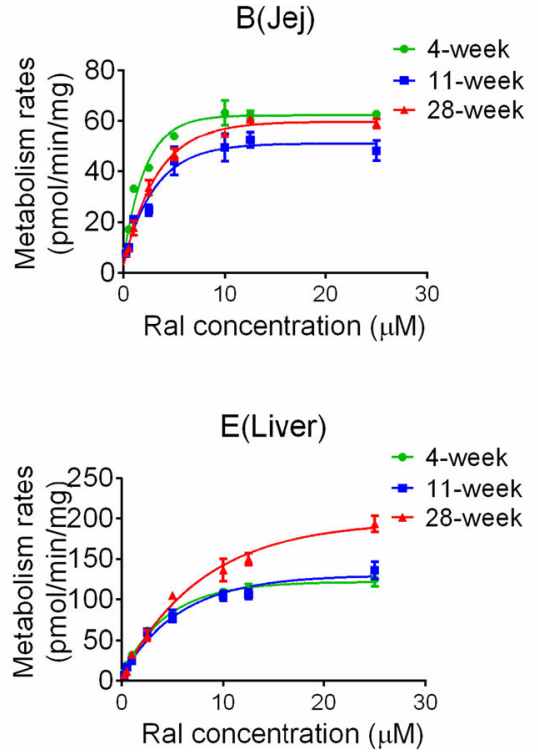

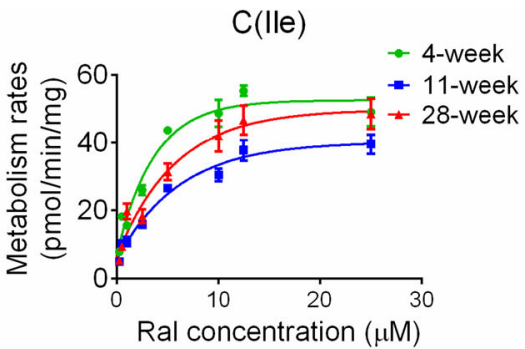

$\mathrm{F}($ Clint $)$

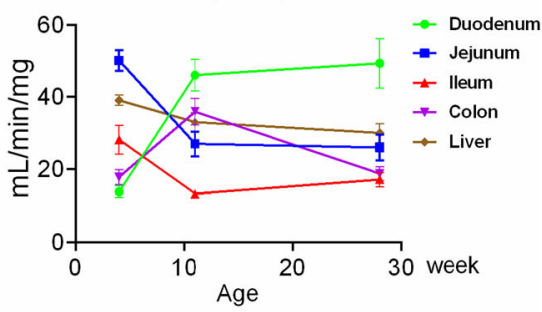

Fig. 4 Regional Glucuronidation and clearance of raloxifene -6-glucuronide in rat S9 fraction. The glucuronidation reaction was carried out for $60 \mathrm{~min}$ at $37^{\circ} \mathrm{C}$ with $0.125,0.25,0.5,1,2.5,5,10,12.5,25 \mu \mathrm{M}$ raloxifene. The $S 9$ enzyme fraction of rat were made from duodenum (Duo), Jejunum (Jej), ileum (lle), colon and liver used in the study, the metabolic clearance of raloxifene to metabolite by each enzyme is given as the Vmax/Km ratio. Each column represents the mean and error bars indicate the S.D $(n=3)$. 


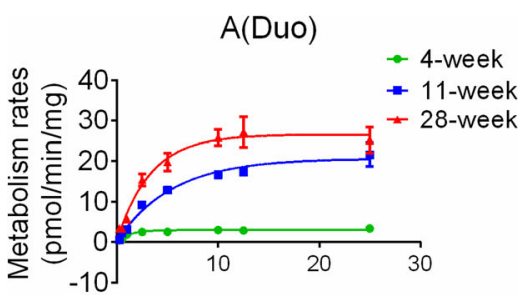

Ral concentration $(\mu \mathrm{M})$

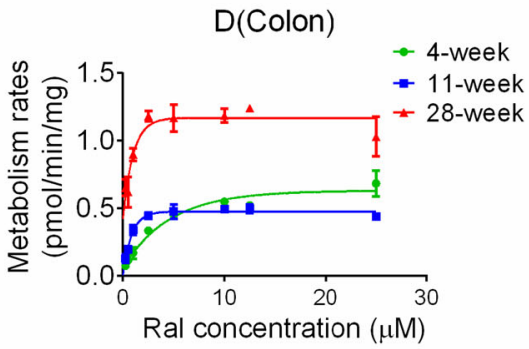

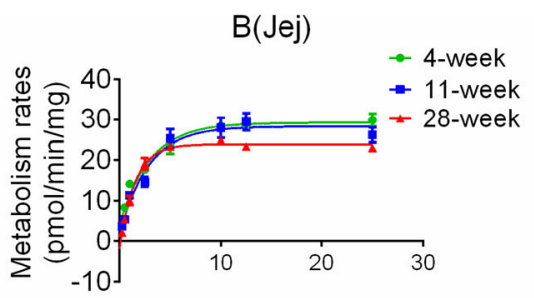

Ral concentration $(\mu \mathrm{M})$

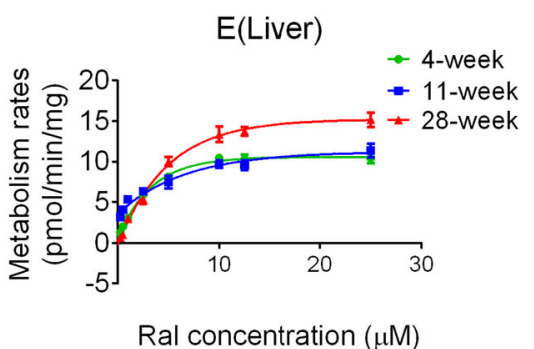

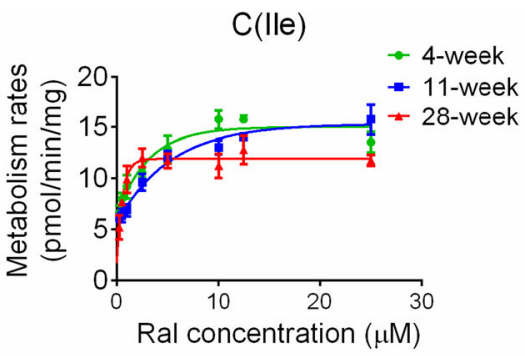

$\mathrm{F}($ Clint $)$

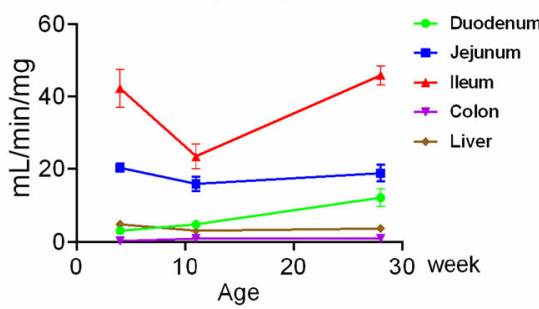

Fig. 5 Regional Glucuronidation and clearance of raloxifene $-4^{\prime}$-glucuronide in rat $S 9$ fraction. The glucuronidation reaction was carried out for $60 \mathrm{~min}$ at $37^{\circ} \mathrm{C}$ with $0.125,0.25,0.5,1,2.5,5,10,12.5,25 \mu \mathrm{M}$ raloxifene. The S9 enzyme fraction of rat were made from duodenum (Duo), Jejunum (Jej), ileum (lle), colon and liver used in the study, the metabolic clearance of raloxifene to metabolite by each enzyme is given as the Vmax/Km ratio. Each column represents the mean and error bars indicate the S.D $(n=3)$.

(19.3\%). The plasma ratios of Ral-6-G vs Ral-4'-G were 1.68 and 0.04 at 4 -week and 3.93 and 0.44 at 11 -week, respectively (Table IV), suggesting that metabolic rates at 4-weeks were slower than those at 11-week. When raloxifene was administered through IV route, the terminal half-life of raloxifene was significantly longer at 11 -week $(5.98 \pm 1.16 \mathrm{~h})$ compared to that at 4 -week $(3.76 \pm 0.69 \mathrm{~h})$, while half-lives of Ral-6-G and Ral-4'-G were similar at these two ages (Fig. 6B, Table III).

\section{Estimation of $\operatorname{In} \operatorname{Viv}_{i v o}$ Glucuronidation}

The in vivo glucuronidation capability was estimated using the ratio of $\mathrm{Ral}-6-\mathrm{G} / \mathrm{Ral}$ and $\mathrm{Ral}-4^{\prime}-\mathrm{G} / \mathrm{Ral}$. The results showed that the ratios of Ral-6-G/Ral were 1.68 and 3.93 at 4-week and I I-week, respectively, and the ratios of Ral-4'-G/Ral were 0.04 and 0.44 at 4-week and I I-week, respectively (Table IV). The in vivo glucuronidation estimation indicated that in vivo glucuronide exposure at 4-week is significantly lower than those at I Iweek, which is consistent with the results observed in in vitro metabolism studies.

\section{DISCUSSION}

Raloxifene undergoes extensive glucuronidation in the GI tract and the liver to afford two metabolites Ral-6-G and Ral-4'-G (Fig. 1), where Ral-6-G is the major metabolite compared to Ral-4'-G (Fig. 2). We determined raloxifene glucuronidation in different regions using S9 fractions prepared from rats at different ages. The results showed that in the duodenum, the metabolic rates for both Ral-6-G and Ral4'-G were significantly lower at 4-week compared to that of 11-and 28-weeks (Fig. 3, 4, 5). The total clearance (Ral-6-G and Ral-4'-G) was gradually decreased in the GI tract from duodenum, jejunum, ileum, and colon at all three ages other than 4-week of the duodenum (Fig. 3F). The clearance for each metabolite in the GI tract and the liver was age and region dependent (Fig. 4F, 5F). The $\mathrm{Km}$ values in different regions at different ages were fluctuant (Table I and II). PK studies showed that the oral bioavailability of raloxifene was significantly higher at 4 weeks when compared to that at 11 weeks (Table IV, Fig. 6). In addition, raloxifene half-life was significantly longer at 11 weeks when compared to that at 4 weeks (Table III, Fig. 6).

Age is known to affect intestinal function (16) and agedependent glucuronidation in the GI tract and the liver have been reported in rodents and humans $(17,18)$. Raloxifene is administered through oral route and undergoes glucuronidation, resulting in low oral bioavailability. In most of the clinical trials, regardless of what age, raloxifene's dose (i.e., $60 \mathrm{mg}$ / day) was same as that in postmenopausal women. However, it is not clear whether raloxifene's disposition and in vivo exposure are age dependent. In this study, we determined raloxifene's metabolism and PK profiles at different ages in F344 rats to address these concerns. It was reported that rats are sexually mature at 6 weeks and socially mature at around 56 months (20-25 weeks) $(19,20)$. Therefore, we conducted the experiments using F344 rats at the age before sexually mature (i.e., 4 weeks old), after sexually but before socially mature (i.e., 11 weeks old), and after socially mature (i.e., 28 weeks old) and 


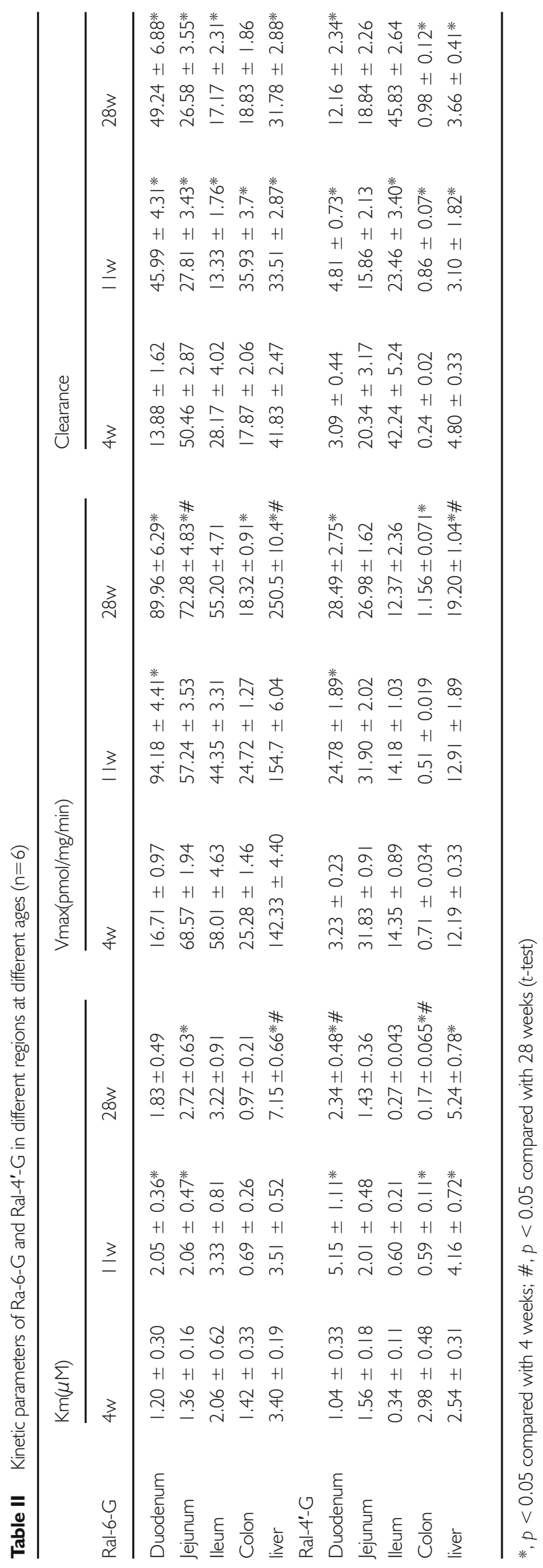


A
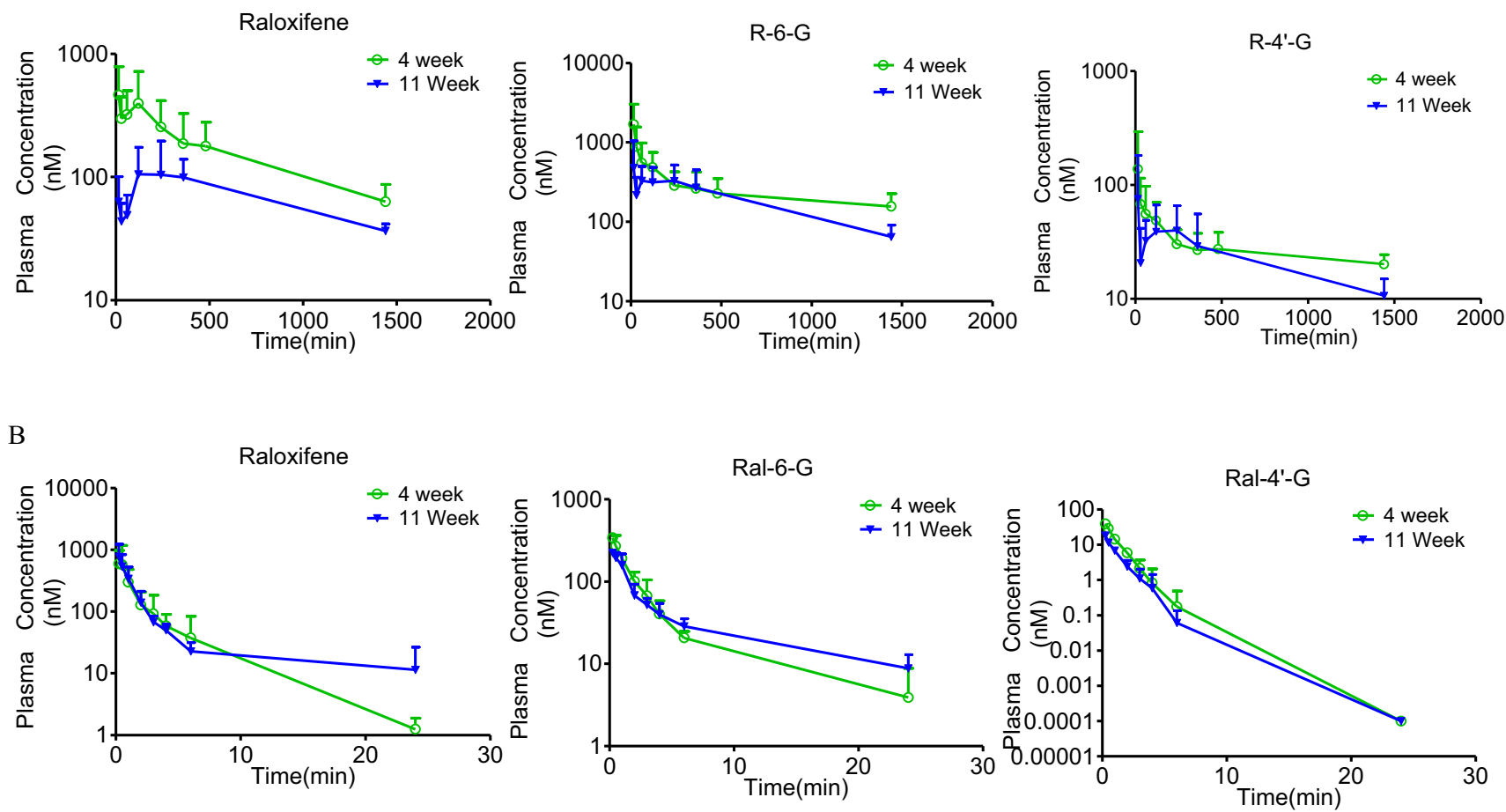

Fig. 6 Plasma concentration versus time profiles of raloxifene and its glucuronides after oral administration (A) and intravenous administration (B) at 4-and I Iweek $(n=5)$. Green line, 4 weeks; Blue line, I I weeks. Raloxifene administered at $10 \mathrm{mg} / \mathrm{kg}$ by oral or $2 \mathrm{mg} / \mathrm{kg}$ by intravenous to Fisher 344 rats. Each symbol represents the mean and the error bars indicate the S.D.

expect to determine the impact of both body and social status on the disposition and oral bioavailability of raloxifene. A $10 \mathrm{mg} / \mathrm{kg}$ dose (human equivalent dose, $96 \mathrm{mg} / \mathrm{kg}$ ) was used in the oral PK studies, which is slightly (1.6-fold) higher than that in human to ensure the measurement of Ral-4'-G in the plasma.

We determined the impact of age on raloxifene oral bioavailability, which has never been reported previously, using rats at 4 - and 11-week since the total raloxifene glucuronidation clearance at 11-week is similar as that at 28-week. The results showed that the absolute bioavailability $\left(\mathrm{F}^{\mathrm{O}} \%\right)$ of raloxifene at 4-week $(75.4 \%)$ was significantly higher than that at 11-week (19.3\%, Table IV, Fig. 6A). It was reported that raloxifene PK could be affected by intestinal glucuronidation (21), however, the impact of different intestinal segments on raloxifene oral bioavailability is unknown. Usually, the jejunum and ileum are believed to be the major drug disposition segments and the duodenum is treated as a breaking throw organ. For raloxifene, we found that duodenum and colon metabolic clearances were significantly lower at 4-week than that at 11-week (Table I). Since colon is the last part of the GI tract and the chance for raloxifene to be absorbed in

Table III Pharmacokinetic parameters of raloxifene after intravenous to Fisher 344 female rats $(n=5$, parameters represent mean \pm SD)

\begin{tabular}{|c|c|c|c|c|c|c|}
\hline \multirow[t]{2}{*}{ Parameters } & \multicolumn{2}{|l|}{ Raloxifene } & \multicolumn{2}{|l|}{ Raloxifene-6-glu } & \multicolumn{2}{|l|}{ Raloxifene-4'-glu } \\
\hline & 4 weeks & II weeks & 4 weeks & I I weeks & 4 weeks & I I weeks \\
\hline $\mathrm{TI} / 2(\mathrm{~h})$ & $3.76 \pm 0.69$ & $5.98 \pm 1.16^{*}$ & $4.08 \pm 2.02$ & $8.86 \pm 2.50^{*}$ & $0.70 \pm 0.20$ & $0.72 \pm 0.16$ \\
\hline $\operatorname{Tmax}(h)$ & $0.33 \pm 0.12$ & $0.25 \pm 0.0$ & $0.33 \pm 0.12$ & $0.40 \pm 0.30$ & $0.33 \pm 0.12$ & $0.25 \pm 0.0$ \\
\hline Cmax(nmol/L) & $676.0 \pm 421.7$ & $772.2 \pm 360.69$ & $362.0 \pm 22.2$ & $231.0 \pm 7.67$ & $43.17 \pm 7.31$ & $18.62 \pm 1.60 *$ \\
\hline$A \cup C_{0 \sim \mathrm{t}}(\mathrm{nmol} \mathrm{h} / \mathrm{L})$ & $1 \mid 82.23 \pm 746.89$ & $1298.23 \pm 462.28$ & $774.4 \pm 203.8$ & $766.29 \pm 115.28$ & $47.06 \pm 5.09$ & $21.58 \pm 2.55^{*}$ \\
\hline$A \cup C_{0 \sim \infty}(\mathrm{nmol} h / \mathrm{L})$ & $1182.23 \pm 746.90$ & $1298.23 \pm 462.29$ & $774.4 \pm 203.9$ & $766.29 \pm 115.29$ & $47.06 \pm 5.10$ & $21.58 \pm 2.56 *$ \\
\hline $\mathrm{Vz}(\mathrm{L} / \mathrm{kg})$ & $27.72 \pm 13.74$ & $27.9 \pm 6.12$ & $29.2 \pm 12.82$ & $61.2 \pm 10.34 *$ & $89.28 \pm 24.03$ & $198.04 \pm 33.73 *$ \\
\hline $\mathrm{CL}(\mathrm{L} / \mathrm{h} / \mathrm{kg})$ & $4.92 \pm 2.20$ & $3.4 \pm 1.19$ & $5.56 \pm 1.38$ & $5.02 \pm 0.98$ & $89.63 \pm 10.86$ & $193.75 \pm 26.65^{*}$ \\
\hline MRT(h) & $2.74 \pm 0.32$ & $3.68 \pm 1.57$ & $3.37 \pm 1.52$ & $5.89 \pm 0.93$ & $0.90 \pm 0.28$ & $0.91 \pm 0.16$ \\
\hline
\end{tabular}

*, $p<0.05$ compared with 4 weeks (unpaired t-test) 
Table IV Pharmacokinetic parameters of raloxifene after oral administration to Fisher 344 female rats $(n=5$, parameters represent mean \pm SD, $F$ was calculated by dividing the oral AUCs by the intravenous AUCs corrected by doses)

\begin{tabular}{|c|c|c|c|c|c|c|}
\hline \multirow[t]{2}{*}{ Parameters } & \multicolumn{2}{|l|}{ Raloxifene } & \multicolumn{2}{|l|}{ Raloxifene-6-glu } & \multicolumn{2}{|l|}{ Raloxifene-4'-glu } \\
\hline & 4 weeks & II weeks & 4 weeks & II weeks & 4 weeks p.o. & II weeks \\
\hline $\mathrm{TI} / 2(\mathrm{~h})$ & $10.67 \pm 3.44$ & $54.76 \pm 29.35 *$ & $15.53 \pm 4.15$ & $|1.1| \pm 2.98$ & $18.56 \pm 6.64$ & $16.97 \pm 5.64$ \\
\hline $\operatorname{Tmax}(\mathrm{h})$ & $1.67 \pm 0.47$ & $2.67 \pm 1.15$ & $0.25 \pm 0.0$ & $3.5 \pm 1.91$ & $2.5 \pm 0.87$ & $3.6 \pm 1.67$ \\
\hline Cmax(nmol/L) & $617.75 \pm 189.59$ & $74.13 \pm 28.14 *$ & $2100.75 \pm 982.9$ & $491.25 \pm 158.92 *$ & $23.34 \pm|3.6|$ & $51.86 \pm 32.85$ \\
\hline$A \cup C_{0} \sim(n m o l h / L)$ & $4456.78 \pm 1328.32$ & $1254.57 \pm 296.0 * 7$ & $7531.83 \pm 2105.29$ & $4926.03 \pm 2006.77$ & $\mid 86.73 \pm 61.54$ & $554.36 \pm 340.19$ \\
\hline$A \cup C_{0 \sim \infty}(n m o l h / L)$ & $13,370.35 \pm 3984.95$ & $4474.85 \pm 1214.26 *$ & $9264.15 \pm 2589.51$ & $6069.23 \pm 2119.21$ & $250.22 \pm 82.46$ & $765.63 \pm 381.83 *$ \\
\hline$V_{z}(\mathrm{~L} / \mathrm{kg})$ & $12.61 \pm 4.60$ & $363.87 \pm 42.15^{*}$ & $8.3 \pm 1.89$ & $60.48 \pm 26.11 *$ & $376.25 \pm 166.83$ & $876.03 \pm 640.53$ \\
\hline $\mathrm{CL}(\mathrm{L} / \mathrm{h} / \mathrm{kg})$ & $0.83 \pm 0.26$ & $5.21 \pm 2.26^{*}$ & $0.40 \pm 0.13$ & $3.75 \pm 1.01 *$ & $14.02 \pm 2.87$ & $33.32 \pm 14.77 *$ \\
\hline $\operatorname{MRT}(h)$ & $7.83 \pm 1.44$ & $11.14 \pm 0.93 *$ & $8.14 \pm 1.58$ & $8.72 \pm 0.69$ & $18.56 \pm 6.64$ & $9.4 \pm 0.76^{*}$ \\
\hline$F(\%)$ & $75.4 \%$ & $19.3 \%$ & & & & \\
\hline In vivo glucuronidation & & & 1.68 & 3.93 & 0.04 & 0.44 \\
\hline
\end{tabular}

*, $p<0.05$ compared with 4 weeks (t-test)

the colon is low it is plausible that significant amount of drug was absorbed in the duodenum, resulting in different in vivo exposure. This is an interesting evidence showing that duodenum disposition could dominate drug oral bioavailability. The in vivo metabolism estimation (Table IV) confirmed that lower metabolic rate at 4-week is associated with high raloxifene oral bioavailability at 4-week. Age-dependent oral bioavailability suggests that raloxifene dose should be carefully considered when administered at different ages in clinical trials.

Another interesting finding in PK studies is age-dependent enterohepatic recycling (EHR). In the PK study, double absorption peaks and long terminal half-life in the oral PK profiles (Fig. 6), which are two typical characters of EHR (22), clearly demonstrated the existence of EHR. In addition, at least Ral-6-G is a good substrate of MRP2 efflux transporter (23), which is a key factor to facilitate EHR mediated by glucuronidation pathway (24). When compared EHR at 4- and 11-week, we found that the raloxifene half-life was significantly shorter at 4-week, suggesting that the efficiency of EHR at 4-week is lower. The possible reasons for low recycling efficiency at 4-week could be age-dependent efflux transporter (e.g., MRP2) expression and age-dependent intestinal microbiota, which hydrolyzes raloxifene glucuronide to facilitate raloxifene's recycling via the glucuronidation pathway (25, 26).

In vitro metabolism study showed that the total raloxifene glucuronidation is age-dependent but is only significant in the duodenum (Fig. 3). Before sexually mature (i.e., 4-week), the total glucuronidation rate is significantly lower than those at the elder ages (i.e., 11-, 28-week). The intrinsic clearance was gradually decreased from the duodenum to the colon in the GI tract other than 4-week (Fig. 3F), suggesting after sexually mature, the upper part is the major disposition segments in the GI tract. For Ral-6-G and Ral4'-G, the metabolic rates follow the same tendency (Figs. 4 and 5). For Ral-6-G, the clearance of the duodenum and colon is lower than those of jejunum, ileum, and liver at 4week (Fig. 4F). Interestingly, when clearance of duodenum and colon increased at 11-week (green and purple lines), the clearance of jejunum, ileum, and liver (brown, blue, and red lines) decreased, suggesting that these regions may have complementary effect. From 11-week to 28-week, the clearance of the duodenum is static, while the clearance of jejunum, ileum, and liver was also static without decreasing. The clearance of the colon was decreased from 11- to 28week somehow. For Ral-4'-G, clearance of duodenum and colon gradually increased at different ages and a similar complementary tendency was in the other three regions was observed (Fig. 5F). In term of Km, all the segments were smaller at 4-week other than the colon (Table I). These findings suggested that UGTs in the duodenum does not achieve mature status before sexually mature in F344 rats.

The semi-quantification analysis by Western blot showed that the expression of Ugtla in the duodenum was significantly lower at 4-week when compared those at 11- and 28-week (Fig. 7). Lower Ugtla expression at 4-week in the duodenum, which is consistent with those reported earlier (17), is the major reason why glucuronidation at 4-week is significantly lower than those at 11- and 28-week in duodenum (Figs. 3, 4, 5). In the liver, where glucuronidation rates were similar at different ages, the Ugtla expression levels were similar (Fig. 7) at 4-, 11-, and 28-week.

The results also showed that Ral-6-G is the major metabolites for all regions at all ages when compared to Ral-4'-G (Fig. 2). In the duodenum and colon, the ratios of these two metabolites are different at age of 28-week with the other two younger ages, suggesting that the relevant UGT isoforms mediated these two metabolites challenged at older age. In the liver, the ratios of these two metabolites is stable, revealing that the composition of the relevant UGT isoforms are stable 


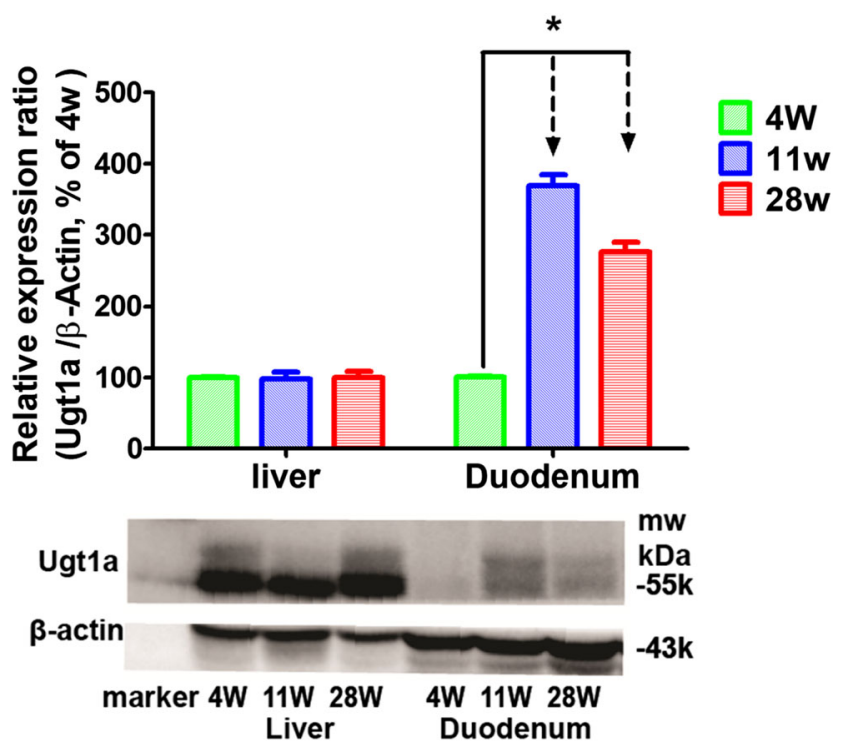

Fig. 7 Ugt la expression in the duodenum and liver microsomes at different ages determined by Western blot. Liver and duodenum microsomal samples were 30 or $60 \mu \mathrm{g} /$ well, respectively. Beta-actin was used as the loading control (*, $p<0.05$ compared to 4-week, t-test)

at different ages. In humans, Ral-6-G is mainly produced by UGT1A1 and 1A9, while Ral-4'-G is mainly produced by UGT1A8 and 1A10. Raloxifene metabolism with rat supersomes has never been studied, probably because of lack of rat UGT supersomes.

Other than glucuronidation, sulfonation by SULTs and oxidation by CYPs were also reported as metabolic pathways for raloxifene $(27,28)$. In addition, the expression of SULTs and CYPs are also age dependent (29). For example, it was reported that the mRNA level of SULTs in the liver in rats was increased with age after born and reached to plateau after 4 weeks (30) and the mRNA levels of the majority of CYP isoforms in the rat liver were increased with age after born and then either maintained the expression or decreased with age from adulthood (29). Therefore, sulfonation and oxidation of raloxifene may also be age dependent. However, the impact of sulfonation and oxidation on raloxifene in vivo exposure is minor. In a previous PK study, we found that the systemic exposure of raloxifene-sulfate was significantly lower (10-180 folds) than those of glucuronides in F344 rats (12). Studies from other research groups revealed that raloxifene oxidative metabolites are almost non-detectable in in vivo studies (31). Therefore, we didn't determine the impact sulfonation and oxidation on raloxifene's in vivo exposure at different ages in this study.

\section{CONCLUSION}

Raloxifene glucuronidation is age dependent in the duodenum in rats probably due to unmatured UGT development in this region at young age, which could significantly increase in vivo raloxifene exposure. In addition, raloxifene enterohepatic recycling efficiency could be lower at young age resulting in different terminal half-life in vivo. These finding suggest that raloxifene dose should be carefully considered in clinical studies when it is used at different ages.

Acknowledgments and Disclosures. No potential conflict of interest was reported by the authors.

\section{FUNDING}

This work was supported by a grant from the National Institute of General Medical Sciences (1R15GM126475-01A1) and Cancer Prevention Research Institute of Texas (CPRIT, RP190672) for Song Gao. This work was also made possible, in part, by services provided from GCC Center for Comprehensive PK/PD and Formulation (CCPF) with CPRIT grant number of RP180748 and National Institute of Minority Health and Health Disparity (U54MD007605) for Dong Liang.

Data Availability The datasets generated during and/or analyzed during the current study are available from the corresponding author on reasonable request.

\section{REFERENCES}

1. Seeman E. Raloxifene. J Bone Miner Metab. 2001;19(2):65-75.

2. Ettinger B, Black DM, Mitlak BH, Knickerbocker RK, Nickelsen $\mathrm{T}$, Genant HK, et al. Reduction of vertebral fracture risk in postmenopausal women with osteoporosis treated with raloxifene: results from a 3-year randomized clinical trial. Multiple outcomes of Raloxifene evaluation (MORE) investigators. JAMA. 1999;282(7):637-45.

3. Cranney A, Tugwell P, Zytaruk N, Robinson V, Weaver B, Adachi $\mathrm{J}$, et al. The Osteoporosis research advisory G. Meta-analyses of therapies for postmenopausal osteoporosis. IV. Meta-analysis of raloxifene for the prevention and treatment of postmenopausal osteoporosis. Endocr Rev. 2002;23(4):524-8.

4. Jolly EE, Bjarnason NH, Neven P, Plouffe L Jr, Johnston CG Jr, Watts SD, et al. Prevention of osteoporosis and uterine effects in postmenopausal women taking raloxifene for 5 years. Menopause. 2003;10(4):337-44.

5. Barrett-Connor E, Mosca L, Collins P, Geiger MJ, Grady D, Kornitzer M, et al. Raloxifene use for the heart trial I. effects of raloxifene on cardiovascular events and breast cancer in postmenopausal women. N Engl J Med. 2006;355(2):125-37.

6. Weickert TW, Weinberg D, Lenroot R, Catts SV, Wells R, Vercammen A, et al. Adjunctive raloxifene treatment improves attention and memory in men and women with schizophrenia. Mol Psychiatry. 2015;20(6):685-94.

7. Kulkarni J, Gavrilidis E, Gwini SM, Worsley R, GriggJ, Warren A, et al. Effect of adjunctive Raloxifene therapy on severity of refractory schizophrenia in women: a randomized clinical trial. JAMA Psychiatry. 2016;73(9):947-54. 
8. Ho TH, Nunez-Nateras R, Hou YX, Bryce AH, Northfelt DW, Dueck AC, et al. A study of combination Bicalutamide and Raloxifene for patients with castration-resistant prostate Cancer. Clin Genitourin Cancer. 2017;15(2):196-202 e191.

9. Lawrence SE, Faught KA, Vethamuthu J, Lawson ML. Beneficial effects of raloxifene and tamoxifen in the treatment of pubertal gynecomastia. J Pediatr. 2004;145(1):71-6.

10. Morello KC, Wurz GT, DeGregorio MW. Pharmacokinetics of selective estrogen receptor modulators. Clin Pharmacokinet. 2003;42(4):361-72.

11. Jeong EJ, Liu Y, Lin H, Hu M. Species- and disposition modeldependent metabolism of raloxifene in gut and liver: role of UGT1A10. Drug Metab Dispos. 2005;33(6):785-94.

12. Du T, Sun R, Li L, Ebuzoeme C, Bui D, Zheng Z, et al. Development and validation of ultra-high-performance liquid chromatography-mass spectrometry method for the determination of raloxifene and its phase II metabolites in plasma: application to pharmacokinetic studies in rats. J Sep Sci. 2020;43(24):4414-23.

13. Sun R, Zhu L, Li L, Song W, Gong X, Qi X, et al. Irinotecanmediated diarrhea is mainly correlated with intestinal exposure to SN-38: critical role of gut Ugt. Toxicol Appl Pharmacol. 2020;398: 115032.

14. Wu B, Basu S, Meng S, Wang X, Hu M. Regioselective sulfation and glucuronidation of phenolics: insights into the structural basis. Curr Drug Metab. 2011;12(9):900-16.

15. Lindstrom TD, Whitaker NG, Whitaker GW. Disposition and metabolism of a new benzothiophene antiestrogen in rats, dogs and monkeys. Xenobiotica. 1984;14(11):841-7.

16. Branca JJV, Gulisano M, Nicoletti C. Intestinal epithelial barrier functions in ageing. Ageing Res Rev. 2019;54:100938.

17. Bolling BW, Court MH, Blumberg JB, Chen CY. Microsomal quercetin glucuronidation in rat small intestine depends on age and segment. Drug Metab Dispos. 201 1;39(8):1406-14.

18. Neumann E, Mehboob H, Ramirez J, Mirkov S, Zhang M, Liu W. Age-dependent hepatic UDP-glucuronosyltransferase gene expression and activity in children. Front Pharmacol. 2016;7:437.

19. Quinn R. Comparing rat's to human's age: how old is my rat in people years? Nutrition. 2005;21(6):775-7.

20. Sengupta P. The laboratory rat: relating its age with Human's. IntJ Prev Med. 2013;4(6):624-30.

21. Kosaka K, Sakai N, Endo Y, Fukuhara Y, Tsuda-Tsukimoto M, Ohtsuka $\mathrm{T}$, et al. Impact of intestinal glucuronidation on the pharmacokinetics of raloxifene. Drug Metab Dispos. 2011;39(9): 1495-502.

22. Roberts MS, Magnusson BM, Burczynski FJ, Weiss M. Enterohepatic circulation: physiological, pharmacokinetic and clinical implications. Clin Pharmacokinet. 2002;41(10):751-90.

23. Kosaka K, Watanabe T, Susukida T, Aoki S, Sekine S, Kume T, et al. Key determinants of the circulatory exposure of organic anions: differences in hepatic uptake between multidrug resistance-associated protein 2 (Mrp2)-deficient rats and wild-type rats. Xenobiotica. 2015;45(6):556-62.

24. Yang G, Ge S, Singh R, Basu S, Shatzer K, Zen M, et al. Glucuronidation: driving factors and their impact on glucuronide disposition. Drug Metab Rev. 2017;49(2):105-38.

25. Li Y, Ning L, Yin Y, Wang R, Zhang Z, Hao L, et al. Age-related shifts in gut microbiota contribute to cognitive decline in aged rats. Aging (Albany NY). 2020;12(9):7801-17.

26. Johnson DR, Guo GL, Klaassen CD. Expression of rat multidrug resistance protein 2 (Mrp2) in male and female rats during normal and pregnenolone-16alpha-carbonitrile (PCN)-induced postnatal ontogeny. Toxicology. 2002;178(3):209-19.

27. Chad Douglas Moore GSY. Cytochrome P450 3A4 regiospecific oxygenation of raloxifene: Evidence for the formation of the diquinone methide. FASEB J. 2008;22, issue S1 Experimental Biology 2008 meeting abstracts(S1):1131-5.

28. Zhou X, Wang S, Sun H, Wu B. Sulfonation of raloxifene in HEK293 cells overexpressing SULT1A3: involvement of breast cancer resistance protein (BCRP/ABCG2) and multidrug resistance-associated protein 4 (MRP4/ABCC4) in excretion of sulfate metabolites. Drug Metab Pharmacokinet. 2015;30(6):42533

29. Xu SF, Hu AL, Xie L, Liu JJ, Wu Q, Liu J. Age-associated changes of cytochrome $\mathrm{P} 450$ and related phase-2 gene/proteins in livers of rats. PeerJ. 2019;7:e7429.

30. Klaassen CD, Liu L, Dunn RT 2nd. Regulation of sulfotransferase mRNA expression in male and female rats of various ages. Chem Biol Interact. 1998;109(1-3):299-313.

31. ScottJA, Da Camara CC, EarlyJE. Raloxifene: a selective estrogen receptor modulator. Am Fam Physician. 1999;60(4):1131-9.

Publisher's Note Springer Nature remains neutral with regard to jurisdictional claims in published maps and institutional affiliations. 